\title{
Expression of the B subunit of Escherichia coli heat-labile enterotoxin in a marine Vibrio and in a mutant that is pleiotropically defective in the secretion of extracellular proteins
}

\author{
ROBIN LEECE ${ }^{1}$ and TIMOTHY R. HIRST ${ }^{2 *}$ \\ ${ }^{1}$ Department of Genetics, University of Leicester, Leicester LE1 7RH, UK \\ ${ }^{2}$ The Biological Laboratory, University of Kent at Canterbury, Canterbury CT2 7NJ, UK
}

(Received 15 August 1991; revised 7 November 1991; accepted 6 December 1991)

\begin{abstract}
A marine Vibrio (designated Vibrio sp. 60) that is related to Vibrio anguillarum was used as a host for a plasmid that encodes the non-toxic B subunit (EtxB) of Escherichia coli heat-labile enterotoxin. Expression of EtxB in Vibrio sp. 60 resulted in the efficient and selective secretion of the $B$ subunit into the extracellular growth medium. This indicated that Vibrio sp. 60, which does not normally produce cholera-like enterotoxins, nonetheless possesses a secretory machinery that permits these toxins to be translocated across its cytoplasmic and outer membranes. Expression of EtxB in a sec mutant of Vibrio sp. 60 (MVT1192), which had previously been shown to be defective in the secretion of several extracellular proteins, resulted in approximately $95 \%$ of the B subunit remaining entrapped within the periplasm of the bacterial cell envelope. This implies that the mutation in MVT1192 defines a locus that determines a common step in the secretion of extracellular proteins, including oligomeric toxins.
\end{abstract}

\section{Introduction}

Bacterial species belonging to the genus Vibrio exhibit a remarkable capacity to secrete proteins through their double-membraned envelopes into the surrounding medium (Finkelstein \& LoSpalluto, 1970; Oishi et al., 1979; Young \& Broadbent, 1982; Neill et al., 1983a; Hirst et al., 1984a; Nishibuchi \& Kaper, 1985; Mercurio \& Manning, 1985; Focareta \& Manning, 1987; Ichige et al., 1988; Hirst \& Welch, 1988). Many of the secreted proteins produced by pathogenic vibrios are important virulence factors, including cholera enterotoxin, haemolysins and neuraminidases, etc., which are secreted, for example by Vibrio cholerae. The molecular mechanism of protein secretion by vibrios is as yet only poorly understood; nonetheless, studies on secretion of enterotoxins by $V$. cholerae have revealed that two independent translocation events are involved (Hirst et al., 1984a; Hirst \& Holmgren, 1987a,b; Hirst, 1991). The first of these encompasses the export of the toxin subunits across the bacterial cytoplasmic membrane. This involves the production of the toxin subunits from a polycistronic

- Author for correspondence. Tel. (0227) 764000 (ext. 7804 or 3950); fax (0227) 763912.
mRNA that encodes separate precursor A and B subunits that carry typical amino-terminal signal sequences, which are cleaved off during the export process. This is followed by the liberation of the mature subunits into the periplasm, where they assemble into a holotoxin complex comprised of one A subunit and five B subunits. The second translocation event involves the transfer of the toxin across the bacterial outer membrane by an apparently selective mechanism that permits the secretion of the toxin into the medium but prevents the release of resident periplasmic proteins.

A similar two-step mechanism may operate for the secretion of other extracellular proteins from vibrios. The proteins that have so far been characterized are synthesized with an amino-terminal signal sequence which would facilitate export across the cytoplasmic membrane into the periplasm, prior to their secretion across the outer membrane (Mekalanos et al., 1983; Mercurio \& Manning, 1985; Focareta \& Manning, 1987; Vimr et al., 1988). Several attempts have been made to analyse the mechanism of protein secretion in Vibrio spp., chiefly through the isolation of mutants which show a phenotypic defect in secretion that results in the accumulation of secreted proteins in the periplasm. A $V$. cholerae mutant that exhibited this phenotype, M14, was isolated by Holmes and coworkers (1975) and had high 
levels of cell-associated cholera toxin. Fractionation experiments showed that the cell-associated toxin indeed accumulates within the periplasm (Hirst \& Holmgren, 1987a). More recently, Ichige et al., (1988), described the isolation of several mutants of a non-pathogenic marine Vibrio (designated Vibrio sp. 60) which exhibits a pleiotropic sec defect in the secretion of extracellular proteins. Studies by Buckley and coworkers on the expression of aerolysin from Aeromonas hydrophila in both Vibrio sp. 60 and its sec mutants revealed that the protein was secreted from the wild-type but not from the sec strains (Wong et al., 1990). As yet, the nature of the genetic defects in either $V$. cholerae M14 or Vibrio sp. 60 mutants remains unknown.

This paper describes the heterologous expression of the B subunit of heat-labile enterotoxin (EtxB) from Escherichia coli (which is structurally and functionally related to the B subunit of cholera toxin) in the wild-type Vibrio sp. 60 strain and in a mutant that is pleiotropically defective in the secretion of extracellular proteins.

\section{Methods}

Bacterial strains and plasmids. Vibrio sp. 60 (strain MVT606) and a secretion-defective mutant of Vibrio sp. 60 (strain MVT1192) were obtained from Dr A. Ichige, University of Tokyo, Japan (Ichige et al., 1988). Both strains were plated onto Luria agar (Miller, 1974) supplemented with an additional $1 \%(\mathrm{w} / \mathrm{v}) \mathrm{NaCl}$ and $50 \mu \mathrm{g}$ rifampicin $\mathrm{ml}^{-1}$. A spontaneous rifampicin-resistant mutant of each strain was isolated and used for all subsequent experiments. E. coli S17-1(RP4-2Tc:: Mu-Km : : Tn 7, Tp Sm), pro $\mathbf{r}^{-} \mathrm{m}^{+}$which contains RP4 integrated into the chromosome (Simon et al., 1983) was used for mobilizing plasmids into Vibrio sp. 60.

Plasmid pMMB68 (Sandkvist et al., 1987) is a derivative of the broad-host range plasmid RSF1010 (Furste et al., 1986) and contains the gene for the B subunit of heat-labile enterotoxin from $E$. coli $\mathbf{H} 74$ 114 of human origin (Dallas, 1983; Leong et al., 1985). The plasmid encodes resistance to $\beta$-lactams. Plasmid pMMB25, also derived from RSF 1010 carries the gene encoding catechol 2,3-dioxygenase ( $x y l E)$ from Pseudomonas putida (Bagdasarian et al., 1983; Hirst \& Holmgren, 1987a). Plasmids pMMB68 or pMMB25, which had previously been transformed into $E$. coli $\mathrm{S} 17-1$, were mobilized into the rifampicinresistant derivatives of MVT606 and MVT1192. This was carried out by mixing exponential-phase cultures of the $E$. coli and Vibrio strain at a ratio of $10: 1$. Then $100 \mu \mathrm{l}$ was spotted onto Luria-agar plates supplemented as described below and incubated for $6 \mathrm{~h}$ at $30^{\circ} \mathrm{C}$. The bacteria were scraped from the agar, serially diluted and transconjugants selected by growth on agar plates containing rifampicin and carbenicillin at the concentrations given below.

Media and growth conditions. Vibrio sp. 60 , with or without plasmids, was inoculated from frozen stocks [kept at $-70^{\circ} \mathrm{C}$ in Luria broth containing $1.5 \%(\mathrm{w} / \mathrm{v}) \mathrm{NaCl}$ and $12.5 \%(\mathrm{v} / \mathrm{v})$ glycerol onto $1.5 \%(\mathrm{w} / \mathrm{v})$ Bacto-agar plates containing Luria broth supplemented with $\mathrm{NaCl}$ to a final concentration of $1.5 \%$ and appropriate antibiotics, rifampicin $\left(50 \mu \mathrm{g} \mathrm{ml}^{-1}\right)$ and carbenicillin $\left(2 \mathrm{mg} \mathrm{ml}^{-1}\right)$, and then incubated overnight at $30^{\circ} \mathrm{C}$. Cells were scraped from the plates and inoculated to an $\mathrm{OD}_{600}$ of $0.02-0.05$ in flasks containing between 10 and $50 \mathrm{ml}$ Luria broth supplemented with $\mathrm{NaCl}$. The cells were cultured at $30^{\circ} \mathrm{C}$ on a rotary shaker, and growth was monitored by measuring the change in $\mathrm{OD}_{600}$. For those strains containing plasmids pMMB68 or pMMB25 IPTG was added to a final concentration of $1.0 \mathrm{mM}$ when the cells reached an $\mathrm{OD}_{600}$ of approximately 0.2 in order to induce the expression of EtxB or catechol 2, 3-dioxygenase, respectively.

Cell fractionation. Samples of culture (usually $1.0 \mathrm{ml}$ ) were taken at different stages of growth. Media and cells were separated by centrifugation in an MSE microfuge (13000 r.p.m., $3 \mathrm{~min}, 20^{\circ} \mathrm{C}$ ), and the cells were resuspended in ice-cold $10 \mathrm{mM}-\mathrm{Tris} / \mathrm{HCl}(\mathrm{pH} \mathrm{8.0})$ with $1 \% \mathrm{NaCl}$ in a volume equivalent to the original sample volume. For determination of toxin concentration in the total cell fraction, the cells were firstly disrupted by sonication for $1 \mathrm{~min}\left(50 \%\right.$ duty cycle) at $4{ }^{\circ} \mathrm{C}$ using an Ultrasonics model W-375 sonicator. For isolation of periplasmic fractions, the cells were washed once in ice-cold $10 \mathrm{~mm}$ Tris/ $\mathrm{HCl}(\mathrm{pH} \mathrm{8.0)}$ with $1 \% \mathrm{NaCl}$, and either subjected to osmotic shock as described by Ichige et al. (1988) or treated with 100 units polymixin $\mathrm{B} \mathrm{ml} \mathrm{m}^{-1}$ for $15 \mathrm{~min}$ at $4^{\circ} \mathrm{C}$. The polymixin-B-treated cells were separated from the released periplasmic contents by centrifugation at $4{ }^{\circ} \mathrm{C}$ in an Eppendorf centrifuge and the cell pellet was resuspended in $10 \mathrm{mM}$ - Tris $/ \mathrm{HCl}\left(\mathrm{pH} 8.0\right.$ ), frozen at $-20^{\circ} \mathrm{C}$, thawed on ice and sonicated for $10 \mathrm{~s}$ as above. The various cell fractions were stored at $-20^{\circ} \mathrm{C}$, prior to further analysis.

Toxin and enzyme assays. The concentration of EtxB in media and cell fractions was determined by a GM1-ganglioside ELISA (GM1ELISA), as described by Svennerholm \& Holmgren (1978), $\beta$ Lactamase activity was assayed by measuring the hydrolysis of nitrocefin (Difco) and catechol 2,3-dioxygenase activity was monitored by measuring the oxidative cleavage of catechol, as described previously (Hirst \& Holmgren, 1987a).

Gel electrophoresis. SDS-PAGE, w/v, $(12.5 \%$ acrylamide) was performed on a Biorad Protean II system using buffer conditions recommended by the manufacturer.

\section{Results}

\section{Expression of EtxB in Vibrio sp. 60}

Previously it was found that the secretory mechanism required for the efficient and selective secretion of cholera-like enterotoxins into the extracellular medium is present in all pathogenic members of the Vibrionaceae, including both aeromonads and vibrios (Hirst \& Holmgren, $1987 a$; Hirst \& Leece, 1991; T. R. Hirst, T. Amin, M. Sandkvist, \& M. Bagdasarian, unpublished observations). To examine whether the non-pathogenic marine micro-organism Vibrio sp. 60 possessed a similar toxin secretory machinery capable of secreting cholera-like enterotoxins into the medium, a plasmid encoding the B subunit of $E$. coli heat-labile enterotoxin (EtxB) was transferred into the strain and the expression and location of EtxB was analysed. To achieve this, a broad host-range plasmid, pMMB68, was used which carries the gene encoding EtxB under the control of an inducible 
Table 1. Heterologous expression of EtxB in Vibrio sp. 60

\begin{tabular}{|c|c|c|c|c|c|c|c|}
\hline \multirow{3}{*}{$\begin{array}{l}\text { Strain } \\
\text { Vibrio sp. } 60\end{array}$} & \multirow{3}{*}{$\begin{array}{l}\text { IPTG induction* } \\
-\end{array}$} & \multicolumn{6}{|c|}{ Concn of EtxB $\left(\mu \mathrm{g} \mathrm{ml}^{-1}\right) \dagger$} \\
\hline & & \multicolumn{2}{|c|}{$\begin{array}{c}\alpha-\mathrm{CT} \\
\text { Media Cells }\end{array}$} & \multicolumn{2}{|c|}{$\begin{array}{c}\alpha-E \operatorname{ExB} \\
\text { Media Cells }\end{array}$} & \multicolumn{2}{|c|}{$\begin{array}{c}\alpha-118 / 87 \\
\text { Media Cells }\end{array}$} \\
\hline & & 0 & 0 & 0 & 0 & 0 & 0 \\
\hline Vibrio sp. $60(\mathrm{pMMB} 68)$ & - & $0 \cdot 11$ & 0.01 & $0 \cdot 1$ & 0.003 & $0 \cdot 1$ & 0.01 \\
\hline Vibrio sp. 60 (рMМB68) & + & $12 \cdot 6$ & $3 \cdot 4$ & $15 \cdot 8$ & 5.8 & $16 \cdot 2$ & $7 \cdot 2$ \\
\hline
\end{tabular}

*Vibrio sp. 60 harbouring pMMB68 was grown in the absence $(-)$ or presence $(+)$ of $1 \mathrm{mM}$-IPTG.

$\dagger$ Determined by GM1-ELISA using polyclonal rabbit anti-cholera toxin $(\alpha-C T)$, polyclonal mouse anti-EtxB $(\alpha-E \operatorname{txB})$ and mouse monoclonal antibody $(\alpha-118 / 87)$.

tac promoter (Sandkvist et al. 1987). This plasmid was mobilized into a rifampicin-resistant derivative of Vibrio sp. 60, as described. Expression and secretion of EtxB was investigated by growing the cells in Luria broth supplemented with $\mathrm{NaCl}$ to an $\mathrm{OD}_{600}$ of approximately $1 \cdot 0$, followed by the sampling of media and cells for analysis of the B subunit concentration by GM1-ELISA (Table 1). As a control, the wild-type strain which lacked pMMB68 was also tested in this assay. A variety of toxinspecific antibodies were used in the ELISA, including polyclonal sera raised against cholera toxin and EtxB, and a monoclonal antibody against EtxB. The assays showed that the wild-type strain did not produce any detectable cross-reacting cholera-like enterotoxin (Table 1). In contrast, Vibrio sp. 60 harbouring pMMB68 produced high-levels of EtxB whose expression was dependent on the addition of IPTG to the growth medium. At least $70 \%$ of the EtxB that was produced was released into the medium.

Comparison of EtxB expression in the wild-type and a sec mutant of Vibrio sp. 60

An $\quad N$-methyl- $N^{\prime}$-nitro- $N$-nitrosoguanidine (NTG)-induced mutation in Vibrio sp. 60 with a pleiotropic defect in the secretion of extracellular proteins was isolated by Ichige et al. (1988). To establish the extent of the pleiotropic nature of the sec phenotype of this mutant, pMMB68 was mobilized into a rifampicinresistant derivative of strain MVT1192. The expression and cellular distribution of EtxB in this strain was compared with that of the wild-type strain harbouring pMMB68 (Fig. 1). The growth rates and final optical densities of the two strains were similar, but the distribution of EtxB was markedly different. In the sec strain (Fig. $1 b$ ) the majority of the B subunit was located in the cells, with only approximately $5 \%$ being released into the medium during exponential-phase growth. This showed that the sec phenotype exhibited by this mutant also blocks release of EtxB.

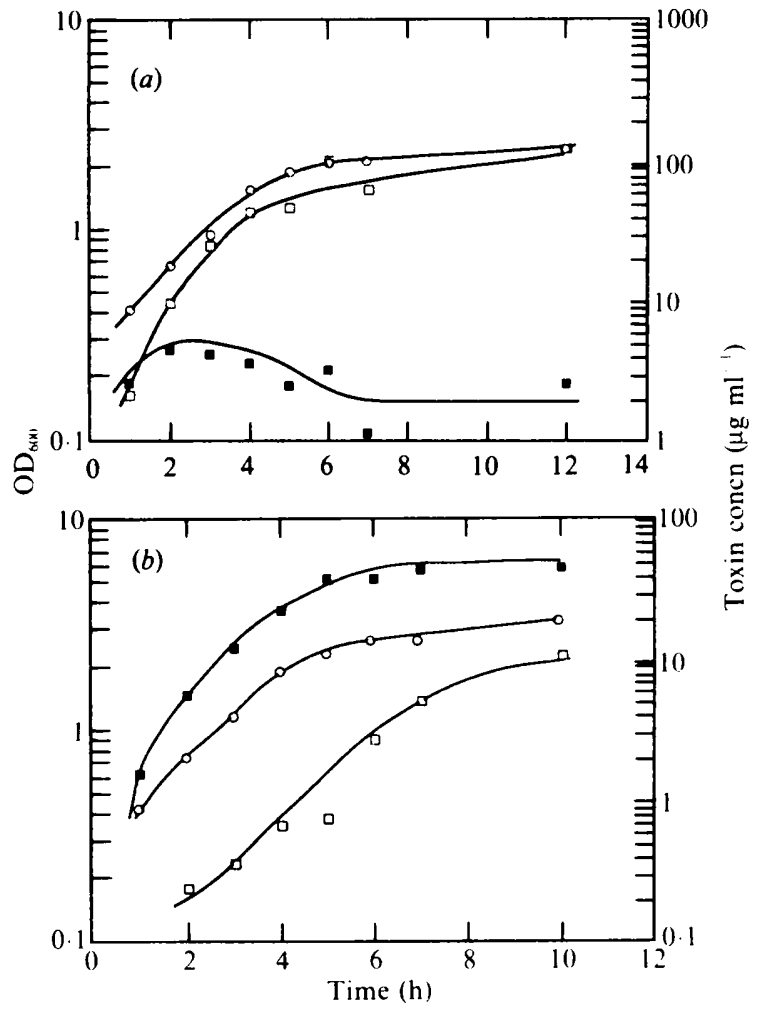

Fig. 1. Expression of EtxB in rifampicin-resistant derivatives of marine Vibrio sp. 60 (a) and a mutant (MVT1192) that is defective in protein secretion $(b)$. Bacteria harbouring plasmid pMMB68 were cultured in Luria broth supplemented with $\mathrm{NaCl}$ and $1 \mathrm{mM}$-IPTG, and growth was monitored by measuring $\mathrm{OD}_{600}(\mathrm{O})$. At the time points indicated the concentration of EtxB in the medium $(\square)$ and in a fraction of sonicated cells $(\boldsymbol{\square})$ was determined by GM1-ELISA.

Samples of media from exponentially growing cultures of the wild-type and the sec strain were analysed by SDSPAGE (Fig. 2). The medium from the wild-type strain lacking pMMB68 contained several major extracellular proteins, whereas the medium from the same strain harbouring pMMB68 contained one additional major protein. This protein had an electrophoretic mobility identical to that of purified EtxB (Fig. 2, compare lanes 1 and 3). Vibrio sp. 60 MVT1192(pMMB68) failed to 


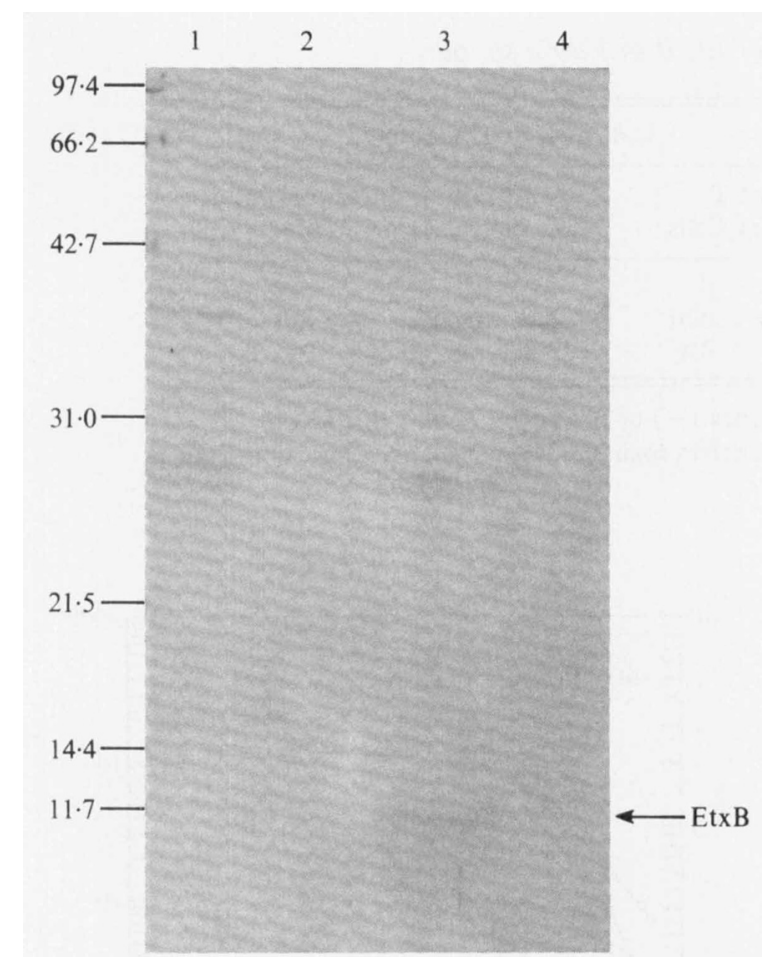

Fig. 2. Medium from exponentially growing cultures of Vibrio sp. 60 and Vibrio sp. 60 (MVT1192) with or without plasmid pMMB68. Strains were inoculated into Luria broth and IPTG was added when the $\mathrm{OD}_{\mathrm{bou}}$ reached $\mathbf{0 . 2}$. Three hours after IPTG induction, the cells and media were separated by centrifugation and $50 \mu \mathrm{l}$ of medium from Vibrio sp. 60 (lane 1), Vibrio sp. 60 (MVT 1192) (lane 2), Vibrio sp. 60 (pMMB68) (lane 3) and Vibrio sp. 60 (MVT1192)(pMMB68) (lane 4) was analysed by SDS-PAGE $(12.5 \%)$. The molecular mass markers used were $(\mathrm{kDa})$ : rabbit muscle phosphorylase $\mathrm{b}, 97.4$; bovine serum albumin, 66.2; hen egg white ovalbumin, 42.7: bovine carbonic anhydrase. 31.0: soybean trypsin inhibitor, 21.5 ; hen egg white lysozyme, 14.4: and the B subunit of heat-labile enterotoxin, 11.7. The arrow indicates the migration position of the $B$ subunit of heat-labile enterotoxin (EtxB).

release sufficient of this protein into the medium for it to be detected by Coomassie Blue staining (Fig. 2, lane 4). Analysis of the same samples by SDS-PAGE without prior heating to $100^{\circ} \mathrm{C}$, resulted in the putative EtxB protein migrating as a discrete oligomer with an apparent molecular mass identical to that of purified EtxB pentamers (data not shown).

To confirm that the integrity of the outer membrane of Vibrio sp. 60 had remained intact during the release of EtxB, the distribution in the medium and cells of the periplasmic enzyme, $\beta$-lactamase, was also determined (Table 2). Ninety-seven percent of the $\beta$-lactamase activity was found to be associated with the cells during the release of EtxB by Vibrio sp. 60(pMMB68) (Table 2). It was concluded that release of EtxB by Vibrio sp. 60 occurs via a selective and efficient secretory mechanism and not by the non-specific release of periplasmic proteins.

\section{Location of the cell-associated EtxB in the sec mutant}

To determine the location of the cell-associated EtxB, two fractionation methods for release of periplasmic proteins were evaluated. A plasmid, pMMB25 (Hirst \& Holmgren, 1987a) which encodes the periplasmic marker enzyme $\beta$-lactamase and the cytoplasmic marker enzyme catechol 2,3-dioxygenase, was introduced into the Vibrio sp. 60 wild-type and the sec mutant. Fractionation by osmotic shock using conditions identical to those reported by Ichige et al. (1988) for the characterization of Vibrio sp. 60 was found to result in the release of only $54-56 \%$ of the periplasmic marker enzyme $\beta$-lactamase. Therefore, an alternative method was used for the release of periplasmic proteins, using polymixin B (Hirst \& Holmgren, 1987a). The treatment of cells with 50-200 units polymixin $\mathrm{B} \mathrm{ml^{-1 }}$ for $15 \mathrm{~min}$ at $4{ }^{\circ} \mathrm{C}$ was sufficient to release more than $80 \%$ of the periplasmic $\beta$-lactamase, with release of less than $0.02 \%$ of catechol 2.3-dioxygenase. Fractionation of Vibrio sp. 60 (MVT1192)(pMMB68) with 100 units polymixin B $\mathrm{ml}^{-1}$ resulted in the release of $87 \%$ of the cell-associated EtxB from the sec mutant (Table 3). It was concluded that EtxB accumulates within the periplasm of the sec mutant and that the pleiotropic defect in secretion prevents the translocation of the toxin subunits from the periplasm across the vibrio outer membrane.

Table 2. Distribution of $\beta$-lactamase and EtxB in the wild-type and a sec mutant of Vibrio sp. 60

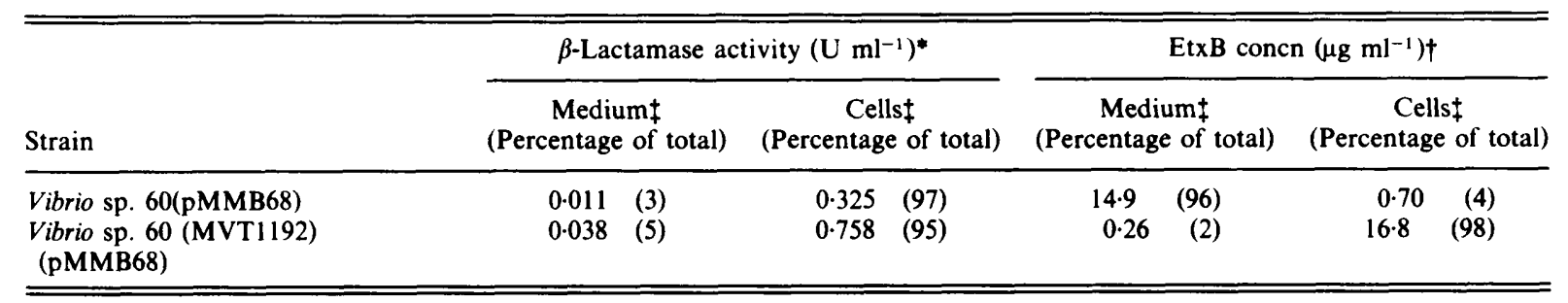

- Determined by hydrolysis of nitrocefin.

$\dagger$ Determined by GMI-ELISA using a mouse monoclonal antibody $(\alpha-118 / 87)$.

$\ddagger$ Culture $(1 \mathrm{ml})$ was centrifuged to separate the cells from the growth medium. The cells were then resuspended in an equal volume of fresh medium and lysed by sonication. 
Table 3. Cellular location of EtxB in the wild-type and a sec mutant of Vibrio sp. 60

\begin{tabular}{lccc}
\hline \hline Strain & \multicolumn{3}{c}{ Concn of EtxB $\left(\mu \mathrm{g} \mathrm{ml}^{-1}\right)^{*}$} \\
\cline { 2 - 4 } & Medium & Periplasm & Extracted cells \\
\hline $\begin{array}{l}\text { Vibrio sp. 60(pMMB68) } \\
\text { Vibrio sp. 60 (MVT1192) }\end{array}$ & $15 \cdot 3$ & 2.4 & $1 \cdot 18$ \\
(pMMB68) & 0.88 & $15 \cdot 4$ & 2.35 \\
\hline \hline
\end{tabular}

* Determined by GM1-ELISA using mouse monoclonal antibody $(\alpha-118 / 87)$.

\section{Discussion}

In this paper it is shown that the B subunit of E. coli heatlabile enterotoxin is efficiently and selectively secreted by Vibrio sp. 60 into the extracellular growth medium. Previous studies on the expression of the $A$ and $B$ subunits of $E$. coli enterotoxin or EtxB alone in $V$. cholerae had revealed that toxin secretion involves two translocation events in which the toxin subunits cross the cytoplasmic membrane as separate precursor polypeptides, followed by the assembly of the mature subunits into an oligomeric complex, and then the secretion of the holotoxin through the outer membrane (Neill et al., $1983 a$; Hirst et al., 1984a, $b$; Hirst \& Holmgren, 1987a, $b$; Sandkvist et al., 1987; Hirst, 1991). In contrast, expression of cholera toxin or the related $E$. coli enterotoxins in $E$. coli or in other members of the Enterobacteriaceae was found to result in the accumulation of assembled toxins within the periplasm (Palva et al., 1981; Neill et al., 1983b; Hirst et al., 1984b; Hofstra \& Witholt, 1984, 1985; Hardy et al., 1988; Hirst \& Leece, 1991; Sixma et al., 1991). The similarity in the efficiency and selectivity of EtxB secretion by Vibrio sp. 60 and $V$. cholerae suggests that the pathway and mechanism of toxin secretion in the two organisms is likely to be identical.

An analysis of media samples from the wild-type Vibrio sp. 60 strain not harbouring the B subunitencoding plasmid showed that this organism doesn't produce a detectable cholera-like enterotoxin. This was not too surprising, since Vibrio anguillarum is a marine micro-organism and a recognized non-pathogen (Janda et al., 1988). What is perhaps more intriguing is the reason why Vibrio sp. 60 should possess a secretory machinery that translocates cholera-like toxins through its envelope into the medium, when it does not normally appear to produce such toxins.

One possible explanation is that all vibrios possess a pleiotropic secretory machinery which is responsible for translocating many different proteins, including oligomeric toxins, across their outer membranes into the extracellular medium. Consistent with this hypothesis is our finding that a sec mutant of Vibrio sp. 60 which is pleiotropically-defective in the secretion of several extracellular proteins, also fails to secrete EtxB into the medium. Similarly, the heterologous expression of aerolysin from Aeromonas hydrophila in Vibrio sp. 60 resulted in aerolysin secretion from the wild-type but not from sec strains (Wong et al., 1990). Thus, the mutation which defines the sec phenotype in MVT1192 would appear to block the secretion of many different proteins and to cause their accumulation within the periplasm. If such a pleiotropic mechanism does indeed exist it would have to be able to discriminate between resident periplasmic proteins and those passing through the periplasm en route to the outer membrane translocation machinery. This would only be conceivable if either all secreted proteins possessed a common structural feature or targeting motif that permitted similar interaction with the outer membrane and/or entry into the secretory machinery, or each secreted protein interacted with a different factor or 'gatepost' at the site of entry into a common secretory machinery. As yet, no universal targeting motif for translocation across the outer membrane has been identified; and moreover such a motif would seem unlikely given the almost certain differences in structure between assembled EtxB pentamers and those of the protease, amylase, DNAase, soluble hemagglutinin and aerolysin that are also secreted from Vibrio sp. 60.

An alternative explanation would be that there is more than one type of secretory machinery, each determining the secretion of a different protein or sub-set of proteins across the outer membrane. In this case, the mutation in MVT1192 must effect the functioning of all of the different translocatory mechanisms in the same way. This could occur if the process of protein translocation across the outer membrane relies on a feature or property of that membrane for efficient translocation to happen. For example, it is conceivable that the constituent lipids, or the integrity of the membrane, or a putative membrane potential (Wong \& Buckley, 1989) could be affected in MVT1192 which causes the pleiotropic inhibition of all outer membrane translocatory mechanisms. Indeed, Ichige et al., (1988) reported that all sec mutants of Vibrio sp. 60 were difficult to transduce with 
phage As3, suggesting a change in cell surface structure. It remains to be established whether the mutations in Vibro sp. 60 define genes which encode a pleiotropic secretory apparatus, or the integrity and normal functioning of several membrane processes, including secretion of extracellular proteins.

We thank Dr Asao Ichige for generously providing the Vibrio sp. 60 strains used in this study. R. L. is an MRC-supported research student. This work was supported by grant 015213 from The Wellcome Trust.

\section{References}

Bagdasarian, M. M., Amann, E., Lurz, R., Ruckert., B. \& Bagdasarian, M. (1983). Activity of the hybrid trp-lac (tac) promoter of Escherichia coli in Pseudomonas putida. Construction of broad-host-range, controlled-expression vectors. Gene 26, 273-282.

Dallas, W. S. (1983). Conformity between heat-labile toxin genes from human and porcine enterotoxigenic Escherichia coli. Infection and Immunity 40, 1072-1077.

Finkelstein, R. A. \& LoSpalluto, J. J. (1970). Production of highly purified cholergen and choleragenoid. Journal of Infectious Diseases 121, S63-S72.

Focareta, T. \& MANning, P. A. (1987). Extracellular proteins of Vibrio cholerae: molecular cloning, nucleotide sequence and characterization of the deoxyribonuclease (DNase) together with its periplasmic location in Escherichia coli K-12. Gene 53, 31-40.

Furste, J. P., Pansegrau, W., Frank, R., Blocker, H., Scholz, P. BAgDASARIAN, M. \& LANKA, E. (1986). Molecular cloning of the RP4 primase region in a multi-host-range tac $P$ expression vector. Gene 48 , 119-131.

Hardy, S. J. S., Holmgren, J., Johansson, S., Sanchez, J. \& Hirst, T. R. (1988). Coordinated assembly of multisubunit proteins: oligomerization of bacterial enterotoxins in vivo and in vitro Proceedings of the National Academy of Sciences of the United States of America 85, 7109-7113.

HIRST, T. R. (1991). Assembly and secretion of oligomeric toxins in Gram negative bacteria. In $A$ Source Book of Bacterial Protein Toxins, pp. 75-100. Edited by J. E. Alouf and J. H. Free. London: Academic Press.

HiRst, T. R. \& Holmgren, J. (1987a). Transient entry of enterotoxin subunits into the periplasm occurs during their secretion from Vibrio cholerae. Journal of Bacteriology 169, 1037-1045.

HiRST, T. R. \& Holmaren, J. (1987b). Conformation of protein secreted across bacterial outer membranes: a study of enterotoxin translocation from Vibrio cholerae. Proceedings of the National Academy of Sciences of the United States of America 84, 7418-7422.

HIRST, T. R. \& WELCH, R. A. (1988). Mechanisms for secretion of extracellular proteins by Gram negative bacteria. Trends in Biochemical Sciences 13, 265-269.

HIRST, T. R. \& LEECE, R. (1991). The phenomenon of toxin secretion in vibrios and aeromonads. Experientia 47, 429-431.

Hirst, T. R., SANChez, J., KAPER, J. B., Hardy, S. J. S. \& Holmgren, J. $(1984 a)$. Mechanism of toxin secretion by Vibrio cholerae investigated in strains harbouring plasmids that encode heat-labile enterotoxins of Escherichia coli. Proceedings of the National Academy of Sciences of the United States of America 81, 7752-7756.

Hirst, T. R., Randall, L. L. \& Hardy, S. J. S. (1984b). Cellular location of heat-labile enterotoxin in Escherichia coli. Journal of Bacteriology 157, 637-642.

HOFSTRA, H. \& WITHOLT, B. (1984). Kinetics of synthesis, processing, and membrane transport of heat-labile enterotoxin, a periplasmic protein in Escherichia coli. Journal of Biological Chemisiry, 259, 15182-15187.
Hofstra, H. \& Witholt, B. (1985). Heat-labile enterotoxin of Escherichia coli: kinetics of association of subunits into periplasmic holotoxin. Journal of Biological Chemistry, 260, 16037-16044.

Holmes, R. K., Vasil, M. L. \& Finkelstein, R. A. (1975). Studies on toxigenesis of Vibrio cholerae. III. Characterization of nontoxinogenic mutants in vitro and in experimental animals. Journal of Clinical Investigation 55, 551-560.

ICHIGE, A., OISHI, K. \& Mizushima, S. (1988). Isolation and characterization of mutants of a marine Vibrio strain that are defective in the production of extracellular proteins. Journal of Bacteriology 170, 3537-3542.

Janda, J. M., Powers, C., Bryant, R. G. \& Abbot, S. L. (1988). Current perspectives on the epidemiology and pathogenesis of clinically significant Vibrio spp. Clinical Microbiology Reviews 1, 245267.

Leong, J., Vinal, A. C. \& Dallas, W. S. (1985). Nucleotide sequence comparison between heat-labile toxin B-subunit cistrons from Escherichia coli of human and porcine origin. Infection and Immunity 48, 73-77.

Mekalanos, J. J., Swartz, D. J., Pearson, G. D. N., Harford, N., GRoYNE, F. \& DE WILDE, M. (1983). Cholera toxin genes: nucleotide sequence, deletion analysis and vaccine development. Nature, London 306, 551-557.

Mercurio, A. \& Manning, P. A. (1985). Cellular location and export of the soluble haemolysin of Vibrio cholerae El Tor. Molecular and General Genetics 200, 472-475.

Miller, J. H. (1974). Experiments in Molecular Genetics. Cold Spring Harbor Laboratory, NY: Cold Spring Harbor Laboratory.

NeILl, R. J.. Ivins, B. E. \& Holmes, R. K. (1983a). Synthesis and secretion of the plasmid encoded heat-labile enterotoxin of Escherichia coli in Vibrio cholerae. Science 221, 289-291.

NeILl, R. J., Twiddy, E. M. \& Holmes, R. K. (1983b). Synthesis of plasmid-coded heat-labile enterotoxin in wild-type and hypertoxinogenic strains of Escherichia coli and in other genera of Enterobacteriaceae. Infection and Immunity 41, 1056-1061.

Nishibuchi, M. \& KAPER, J. B. (1985). Nucleotide sequence of the thermostable direct hemolysin gene from Vibrio cholerae. Journal of Bacteriology 162, 558-564.

OIshi, K., Yokoshima, S., TomiYama, T. \& AIDA, K. (1979). Exohemagglutinins: new products of vibrios. Applied and Environmental Microbiology 38, 169-172.

Palva, E. T., Hirst, T. R., Hardy, S. J. S., Holmgren, J. \& Randall, L. L. (1981). Synthesis of a precursor of the B subunit of heat-labile enterotoxin in Escherichia coli. Journal of Bacteriology, 146, 325-330.

SANDK viST, M., HIRST, T. R. \& BAGDASARIAN, M. (1987). Alterations at the carboxyl terminus change assembly and secretion properties of the B subunit of Escherichia coli heat-labile enterotoxin. Journal of Bacteriology 169, 4570-4576.

Simon, R., Priefer, U. \& Puhler, A. (1983). A broad-host range mobilization system for in vivo genetic engineering: transposon mutagenesis in Gram negative bacteria. Biotechnology 1, 784-791.

Sixma, T. K., Pronk, S. E., Kalk, K. H., Wartna, E. S., Van Zantan, B. A. M., Witholt, B. \& HoL, W. G. J. (1991). Crystal structure of a cholera toxin-related heat-labile enterotoxin from $E$. coli. Nature, London 351, 371-377.

SVENNERHOLM, A. M. \& HOLMGREN, J. (1978). Identification of Escherichia coli heat-labile enterotoxin by means of a ganglioside immunosorbent assay (GMI-ELISA) procedure. Current Microbiology 1, 19-23.

VimR, E. R., Lawrisuk, L., Gallen, J. \& KaPer, J. B. (1988). Cloning and expression of the Vibrio cholerae neuraminidase gene nanH in Escherichia coli. Journal of Bacteriology 170, 1495-1504.

WONG, K. R. \& BUCKLEY, J. T. (1989). Proton motive force involved in protein export from Aeromonas salmonicida. Science 246, 654-656.

Wong, K. R., Mclean, D. M. \& Buckley, J. T. (1990). Cloned aerolysin of Aeromonas hydrophila is exported by a wild-type marine Vibrio strain but remains periplasmic in pleiotropic export mutants. Journal of Bacteriology 172, 372-376

Young, D. B. \& BroADBENT, D. A. (1982). Biochemical characterization of extracellular proteases from Vibrio cholerae. Infection and Immunity 37, 875-883. 